\title{
To the Question of the Influence of the Intensity of Active Centers on the Surface of Mineral Fillers on the Properties of Fine-Grained Concrete
}

\author{
Anvar Ishanovich Adylkhodzhaev, Makhamataliev Irkin Muminovich, Kadyrov Ilkhom \\ Abdullaevich, Shaumarov Said Sanatovich, Ruzmetov Fazliddin Sharifboevich
}

\begin{abstract}
The paper presents the results of experimental research on the evaluation of the possibility of using the indicators of surface activity of dispersed minerals as a criterion for determining the most effective way of their application in cement concrete. The obtained results allow to recommend to use such fillers as: quartz sand, barchan sand, wastes of electro smelting production for filling of cement concretes by the method "filling of cement in concrete": gliege, basalt, wastes of copper smelting production, fly ash of thermal power stations, zeolitecontaining rocks for filling of cement concretes by the method "filling of cement in concrete".
\end{abstract}

Keywords: high quality concrete, mineral filler, active centers, strength, mathematical model, cement filling, filling of sand, gliege, zeolite, ash, sand.

\section{INTRODUCTION}

Nowadays one of the most important directions of improvement of concrete and reinforced concrete products is to ensure high quality of structures through the use of highquality concrete. Modern high quality concretes (HQC) combine a wide range of concretes of various purposes: high-strength and ultra-high-strength concretes [1], selfcompacting concretes (SVB, SCC) [2], self-leveling concretes (SLS), highly corrosion-resistant concretes [3], reactionary powder concretes, including dispersionreinforced concretes (Reaktionspulver beton - RPB or Reactive Powder Concrete - RPC) [4]. These types of concrete meet high requirements in terms of compressive and tensile strength, crack resistance, impact strength, wear resistance, corrosion resistance and frost resistance.

The technology of concrete by now has a wide range of methods that allow to reduce the specific consumption of cement in specific conditions without deterioration of technical properties of concrete. As results of numerous scientific researches and practical experience of modern construction show introduction of mineral fillers as an independent component of concrete and mortar mixtures is one of the most effective ways to increase their efficiency and quality [5-7]. It is necessary to note that among

Revised Manuscript Received on July 18, 2019.

Anvar Ishanovich Adylkhodzhaev, Doctor of Science, Professor, Research and Innovation Deputy Head, Tashkent Institute of Railway Transport Engineers, Tashkent, Uzbekistan.

Makhamataliev Irkin Muminovich, $\mathrm{PhD}$ of Technical Sciences, Professor of the Tashkent Institute of Railway Transport Engineers, Tashkent, Uzbekistan.

Kadyrov Ilkhom Abdullaevich $\mathrm{PhD}$ of Technical Sciences, Tashkent Institute of Railway Transport Engineers, Tashkent, Uzbekistan.

Shaumarov Said Sanatovich, PhD of Technical Sciences, Associate Professor,Tashkent Institute of Railway Transport Engineers, Tashkent, Uzbekistan.

Ruzmetov Fazliddin Sharifboevich, PhD of Technica Sciences,Tashkent Institute of Railway Transport Engineers, Tashkent, Uzbekistan scientists and specialists there is no consensus on the mechanism of influence of mineral fillers on the formation of the structure and properties of the filled concrete.

In the previous studies [8-10] it was noted that there is a connection between the quantitative indicators of strength and operational properties of filled cement compositions and the peculiarity of the distribution of active centers on their surface, the classification of mineral powders of various nature on the efficiency of the impact on the course and course of the processes of binder hydration and the possibility of directional control of the processes of formation of the structure and properties of the resulting material. By the present time properties and characteristics of surface activity of a number of local mineral substances of various genesis used as mineral fillers in cement systems are studied in detail. In particular in researches of Dr. Tsoi V.M. [11] established the basic regularities of the impact of the distribution of adsorption centers on the surface of mineral fillers on the properties of cement compositions. However, in our opinion, it seems expedient to study this direction of modern concrete science in greater depth from the point of view of establishing the features of surfaceactive properties of local mineral raw materials and on this basis the choice of the method of application of mineral fillers in cement compositions.

In this regard, the authors have carried out experimental studies to assess the possibility of using the surface activity of dispersed minerals as a criterion for determining the most effective way of their use in cement concrete.

\section{CHARACTERISTICS OF MATERIALS}

In experimental researches Portland cement of mark M400 D0 of Ahangaran cement industrial complex was used. The chemical composition of Portland cement was characterized by the following content of oxides: $\mathrm{CaO}$ $65,8 \%, \quad \mathrm{SiO}_{2}-22,1 \%, \quad \mathrm{Al}_{2} \mathrm{O}_{3}-4,5 \%, \mathrm{Fe}_{2} \mathrm{O}_{3}-4,2 \%, \mathrm{SO}_{3}$ $0,6 \%, \mathrm{MgO}-1,7 \%, \mathrm{Na}_{2} \mathrm{O}-0,2 \%, \mathrm{~K}_{2} \mathrm{O}-0,4 \%, \mathrm{n}, \mathrm{p}, \mathrm{p},-0,2 \%$. The mineralogical composition of Portland cement was characterized by the following mineral content: C3S $-57,5$ $\%, \mathrm{C}_{2} \mathrm{~S}-17,8 \%, \mathrm{C}_{3} \mathrm{~A}-4,7 \%, \mathrm{C}_{4} \mathrm{AF}-12,5 \%$.

The river quartz sand of May quarry with $\mathrm{M \kappa}=1.81$ and an average density of $-2000 \mathrm{~kg} / \mathrm{m}^{3}$ was used as a fine aggregate. The content of foreign particles did not exceed $0.15 \%$.

The following local natural and technogenic minerals were used as mineral fillers for concrete: gliezh - Angren

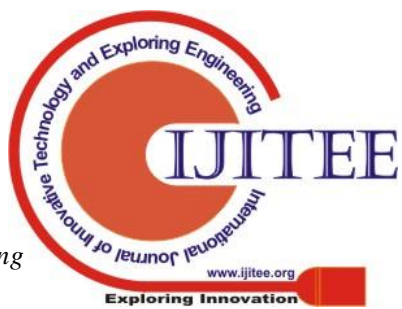




\section{TO THE QUESTION OF THE INFLUENCE OF THE INTENSITY OF ACTIVE CENTERS ON THE SURFACE OF MINERAL FILLERS ON THE PROPERTIES OF FINE-GRAINED CONCRETE}

deposit, sand - Mayskoe quarry, fly ash - Novoangrenskaya TPP, zeolite-containing rock - Beltau deposit.

\section{TESTING METHODOLOGY}

To determine the ultimate strength of fine-grained concrete in bending and compressing, three specimens were made - each beams $4 \times 4 \times 16 \mathrm{~cm}$ in size. After the established mode of hardening the specimens - beams were tested for bending on the device MII-100 and for compression on the testing machine $\mathrm{MC}-500$. To determine the quantitative content of active centers on the surface of these mineral fillers, the method of determining the distribution of adsorption centers (DAC) developed by Prof. Nechiporenko A.P. [12] was used.

\section{RESULTS AND DISCUSSION}

In order to solve the problem of determining the influence of active centers with a certain acidity (or basicity) on the strength of cement concrete, the studies were conducted on samples of fine-grained concrete of $1: 3$ size $4 \times 4 \times 16 \mathrm{~cm}$, hardened before the test in water. Mineral filler was introduced instead of a part of cement or a part of sand by mass. Concrete mixtures with filler of different types were prepared from the condition of preservation of waterbinding ratio equal to 0.57 . The results of strength test of the samples are given in Table 1.

Table 1 Influence of method and degree of filling on the strength of fine-grained concrete

\begin{tabular}{|c|c|c|c|c|c|c|}
\hline \multirow{3}{*}{ Fuller } & \multicolumn{3}{|c|}{ Cemeat filling } & \multicolumn{3}{|c|}{ Sand filling } \\
\hline & \multirow{2}{*}{$\begin{array}{l}\text { filling } \\
\text { leve! }\end{array}$} & \multicolumn{2}{|c|}{$\begin{array}{c}\text { strengh period } 25 \\
\text { days, MP a }\end{array}$} & \multirow{2}{*}{$\begin{array}{l}\text { filling } \\
\text { Ieve! }\end{array}$} & \multicolumn{2}{|c|}{$\begin{array}{c}\text { srength period } 25 \\
\text { days, MP a }\end{array}$} \\
\hline & & flexure & squexte & & flexuce & פquext \\
\hline 1 & 2 & 3 & 4 & 5 & 6 & 7 \\
\hline Withost filler & $\cdot$ & $\frac{6,2}{100}$ & $\frac{33,1}{100}$ & & $\frac{7,5}{100}$ & $\frac{39,7}{100}$ \\
\hline \multirow{3}{*}{ Gliege } & 10 & $\frac{5,4}{87}$ & $\frac{29,8}{90}$ & 10 & $\frac{7,8}{104}$ & $\frac{37,4}{94}$ \\
\hline & 15 & $\frac{5,2}{36}$ & $\frac{28,1}{85}$ & 20 & $\frac{7,6}{99}$ & $\frac{36,8}{83}$ \\
\hline & 20 & $\frac{4,8}{77}$ & $\frac{26,1}{79}$ & 30 & $\frac{7,4}{99}$ & $\frac{34,8}{88}$ \\
\hline \multirow{3}{*}{ Sasd } & 10 & $\frac{6,4}{71}$ & $\frac{26,0}{72}$ & 10 & $\frac{7,2}{96}$ & $\frac{41,8}{105}$ \\
\hline & 15 & $\frac{3,0}{69}$ & $\frac{18,4}{56}$ & 20 & $\frac{7,3}{97}$ & $\frac{36,9}{93}$ \\
\hline & 20 & $\frac{2,4}{40}$ & $\frac{15,6}{47}$ & 30 & $\frac{7,2}{96}$ & $\frac{35,6}{90}$ \\
\hline \multirow{3}{*}{ Fy ash } & 10 & $\frac{5,7}{92}$ & $\frac{27,8}{84}$ & 10 & $\frac{7,7}{102}$ & $\frac{63,9}{123}$ \\
\hline & 20 & $\frac{5,1}{82}$ & $\frac{24,8}{75}$ & 20 & $\frac{6,9}{93}$ & $\frac{38,9}{98}$ \\
\hline & 30 & $\frac{6,6}{75}$ & $\frac{23,2}{70}$ & 30 & $\frac{6.5}{87}$ & $\frac{35,7}{90}$ \\
\hline \multirow{3}{*}{ Zeolihe-codaining rock } & 10 & $\frac{6,9}{112}$ & $\frac{31,8}{96}$ & 10 & $\frac{7,9}{105}$ & $\frac{69,7}{125}$ \\
\hline & 20 & $\frac{7,4}{119}$ & $\frac{28,8}{87}$ & 20 & $\frac{7,5}{100}$ & $\frac{64,5}{112}$ \\
\hline & 30 & $\frac{6,5}{105}$ & $\frac{26,1}{79}$ & 30 & $\frac{7,0}{93}$ & $\frac{39,0}{98}$ \\
\hline
\end{tabular}

In order to expand the understanding of the nature of the formation of physical and mechanical parameters of the projected composite, graphoanalytical analysis of the relationship between the compressive strength of concrete when filling the cement with various micro-fillers with an established quantitative content of active centers on the surface of these mineral fillers (Fig. 1).

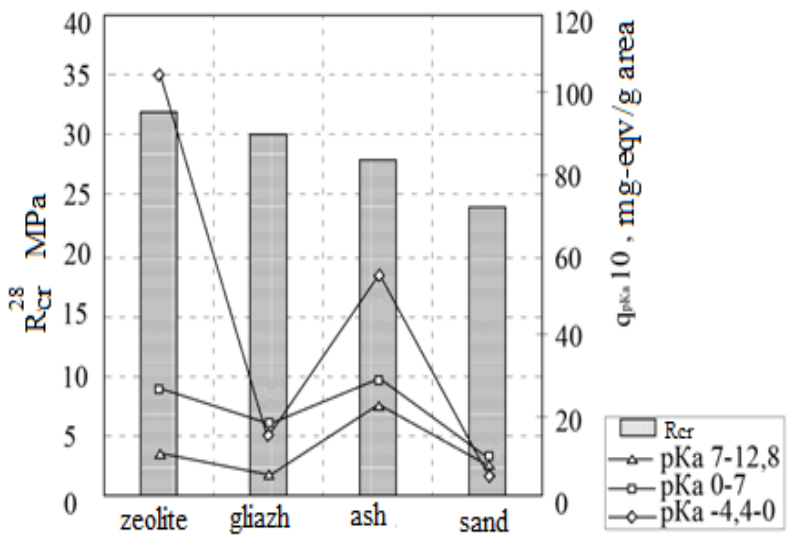

Fig.1. Strength of fine-grained concrete depending on the intensity of active centers on the surface of mineral

fillers in the method of filling cement in concrete

As can be seen from Fig. 1, there is no clear link between the compressive strength of concrete and the intensity of active centers in any single region of acidity. In order to determine the complex influence of the active centers in different areas of acidity of the surface of mineral fillers on the strength of concrete during the filling of cement, a regression analysis was carried out. Table 2 presents the data of statistical processing of the results of this type of analysis.

Table 2 Data of statistical processing of experimental results

\begin{tabular}{|l|l|l|l|l|l|}
\hline \multirow{3}{*}{ Fillers } & \multicolumn{3}{|c|}{$\begin{array}{c}\text { Total intensity of active centres in the } \mathrm{pHa}, \\
\mathrm{mg} \text {-eqv/g area }\end{array}$} & \multicolumn{2}{|c|}{$\begin{array}{c}\text { Strength of concrete } \\
\mathrm{R}_{\mathrm{se}^{28}}{ }^{28}, \mathrm{MPa}\end{array}$} \\
\cline { 2 - 6 } & $\begin{array}{c}\mathrm{X}_{1} \\
-4,4 \text { to } 0\end{array}$ & $\begin{array}{c}\mathrm{X}_{2} \text { from } 0 \text { to } \\
7\end{array}$ & $\begin{array}{c}\mathrm{X}_{3} \text { from 7 to } \\
12,8\end{array}$ & Fact & Estimated \\
\hline Gliege & 15,39 & 18,32 & 5,85 & 38,8 & 39,0 \\
\hline Quartz sand & 5,12 & 10,29 & 7,53 & 41,8 & 41,1 \\
\hline Zeolite-containing rock & 104,54 & 25,25 & 10,63 & 49,70 & 49,5 \\
\hline Fly ash & 54,97 & 29,71 & 23,17 & 48,90 & 48,60 \\
\hline
\end{tabular}

Table 3 Statistical characteristics of the regression equation

\begin{tabular}{|c|c|c|c|c|}
\hline Factor & R-quadrant & Standard error & Fisher's Criterio & Relevancy P \\
\hline$R_{50} 28$ & 0,99 & 0,1948 & 676,984 & $3,98 \cdot 10^{-7}$ \\
\hline
\end{tabular}

As variables in the regression analysis, the total intensities of the active centers in the pKa area are taken as follows: $\mathrm{X}_{1}$ - from -4.4 to $0, \mathrm{X}_{2}$ - from 0 to 7 , and $\mathrm{X}_{3}$ - from 7 to 12.8. As a response function, the compressive strength of concrete at the age of 28 days of normal storage $\left(\mathrm{R}_{\mathrm{SQ}} 28\right.$, $\mathrm{MPa}$ ) is assumed. After statistical processing of experimental data the following mathematical model (regression equation) is obtained:

$\mathrm{R}_{\mathrm{SQ}} 28=50,728-0,576 \mathrm{X}_{1}-10,489 \mathrm{X}_{2}+12,31 \mathrm{X}_{3}-0,026$ $\mathrm{X} 12+0,61 \mathrm{X} 22+0,396 \mathrm{X}_{3}^{2}+0,115 \mathrm{X}_{1} \mathrm{X}_{2}+0,077 \mathrm{X}_{1} \mathrm{X}_{3}-$ $1,34 \mathrm{X}_{2} \mathrm{X}_{3}$. 


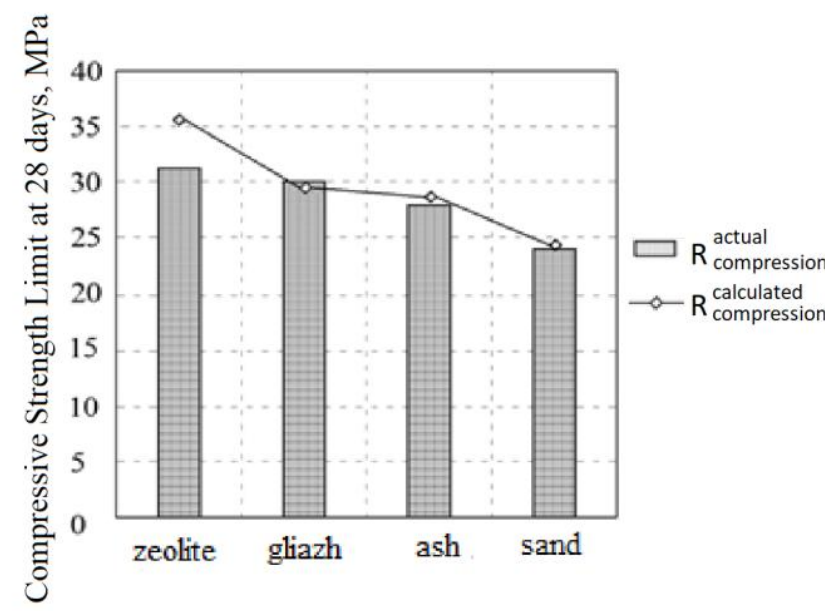

Fig.2. Actual and calculated values of strength of finegrained concrete in the method of filling cement in concrete

that active surface centers in the area of pKa from $-4,4$ to 0 and 0 to 7 create preconditions for deeper flow of processes of hydration at the expense of strengthening of hydraulic activity of mineral filler. Active centers in the region of $\mathrm{pKa}$ from 7 to 12.8 are responsible for the hydrophilicity of the surface of mineral fillers and directly affect the capillary porosity of concrete, contributing to their reduction.

Increase of strength of concrete at application of mineral fillers for replacement of a part of sand, as it has been shown in work [11], first of all is connected with modification of a pore structure. At the same time, a close statistical connection between the content of active surface centers of fillers and the indicators of structural porosity of the material has been established. In this connection, it is of interest to establish the mechanism of action of the active centers of mineral fillers on the strength of concrete during the filling of sand.

The relationship between the intensity of active centers of various acidity on the surface of mineral fillers and the strength of fine-grained concrete when filling the sand study was carried out at a value of the filling degree of $10 \%$ by mass. Data on the composition and properties of concrete mixture and concrete are given in Table 1.

Fig. 3 graphically shows the relationship between the strength of fine-grained concrete at sand filling and the intensity of adsorption centers on the surface of mineral fillers. As can be seen from Fig. 3, when using the filler in the sand, a correlation dependence close to the linear one between the strength of concrete and the content of adsorption centers in the region of $\mathrm{pKa}$ from -4.4 to 0 , from 0 to 7 and from 7 to 12.8 is traced. The filler from zeolitecontaining rock falls out of the general series.

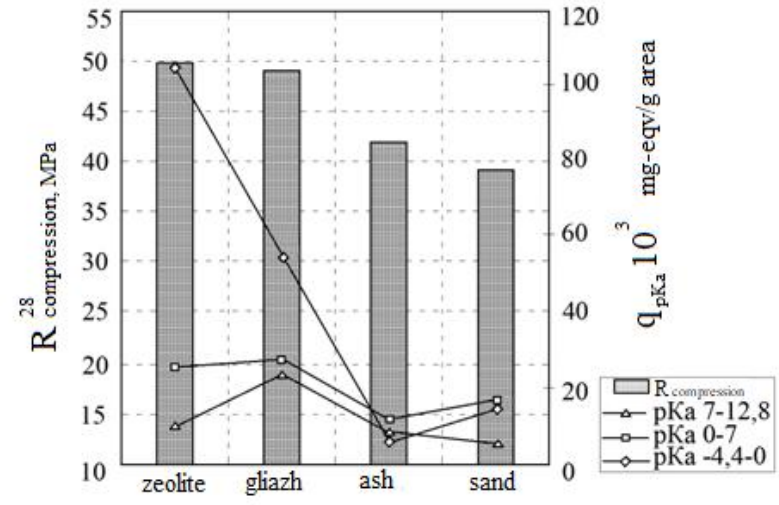

Fig.3. Strength of fine-grained concrete depending on the intensity of the active centers on the surface of mineral fillers in the method of filling the sand in the concrete

In order to clarify the relationship between the surface activity of mineral fillers and the strength of concrete during the filling of sand in the concrete, a regression analysis was carried out. Table 5 shows the main part of data of statistical processing of regression analysis. In the studies, the total intensity of active centers in the region of $\mathrm{pKa}$ was taken as a variable factor: $X_{1}$ - from -4.4 to $0, X_{2}$ - from 0 to 7 , and $\mathrm{X}_{3}$ - from 7 to 12.8 . As a response function, the compressive strength of concrete at the age of 28 days of normal storage $\left(\mathrm{R}_{\mathrm{SQ}} 28, \mathrm{MPa}\right)$ is accepted. After statistical processing of the obtained data of the regression analysis, the following mathematical model (regression equation) was obtained:

$\mathrm{R}_{\mathrm{SQ}} 28=39,98+0,114 \mathrm{X}_{1}-0,298 \mathrm{X}_{2}+0,49 \mathrm{X}_{3}+0,026$ $\mathrm{X}_{1}^{2}+0,052 \mathrm{X}_{2}^{2}+0,027 \mathrm{X}_{3}^{2}-0,102 \mathrm{X}_{1} \mathrm{X}_{2}+0,054 \mathrm{X}_{1} \mathrm{X}_{3}$ $0,734 \mathrm{X}_{2} \mathrm{X}_{3}$

Table 6 shows the statistical characteristics of the obtained mathematical model, and in Fig. 4 the actual values of strength with the calculated data obtained using the mathematical model.

Table 5 Data of statistical processing of experimental results

\begin{tabular}{|l|l|l|l|l|l|}
\hline \multirow{2}{*}{ Fillers } & \multicolumn{3}{|c|}{$\begin{array}{c}\text { Total intensity of active centres in the } \mathrm{pHa}, \\
\text { mg-eqv/g area }\end{array}$} & \multicolumn{2}{|c|}{$\begin{array}{c}\text { Strength of concrete } \\
\mathrm{R}_{\mathrm{se}^{28}}, \mathrm{MPa}\end{array}$} \\
\cline { 2 - 6 } & $\begin{array}{c}\mathrm{X}_{1} \\
-4,4 \text { to } 0\end{array}$ & $\begin{array}{c}\mathrm{X}_{2} \text { from } 0 \text { to } \\
7\end{array}$ & $\begin{array}{c}\mathrm{X}_{3} \text { from 7 to } \\
12,8\end{array}$ & Fact & Estimated \\
\hline Gliege & 15,39 & 18,32 & 5,85 & 38,8 & 39,0 \\
\hline Quartz sand & 5,12 & 10,29 & 7,53 & 41,8 & 41,1 \\
\hline Zeolite-containing rock & 104,54 & 25,25 & 10,63 & 49,70 & 49,5 \\
\hline Fly ash & 54,97 & 29,71 & 23,17 & 48,90 & 48,60 \\
\hline
\end{tabular}

Table 6 Statistical characteristics of the regression equation

\begin{tabular}{|c|c|l|l|l|}
\hline \multicolumn{1}{|c|}{ Factor } & $\mathrm{R}$-quadrant & Standardmistake & Fishers' criteria & Relevancy $\mathrm{F}$ \\
\hline $\mathrm{R}_{\mathrm{sq}}^{28}$ & 0,986 & 0,569 & 263,214 & $1,61 \cdot 10^{-10}$ \\
\hline
\end{tabular}




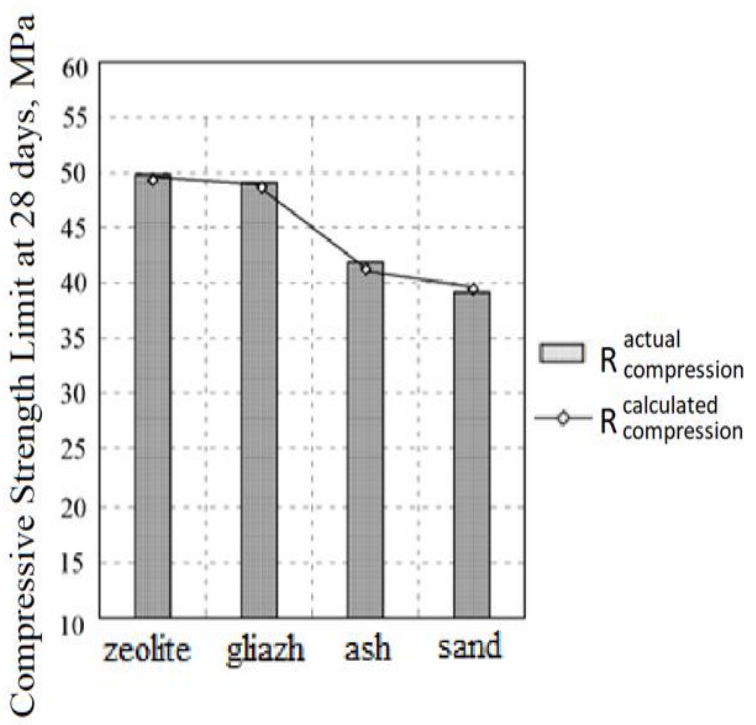

Fig.4. Actual and calculated strength values of finegrained concrete in the method of sand filling in concrete

The analysis of the received mathematical model allows to draw a conclusion that at a way of filling of sand in concrete there is more obvious connection between durability of concrete and intensity of the active centers on a surface of mineral fillers, than at a way of filling of cement in concrete. Thus character of regularity of influence of the active centers in the field of pKa from 0 to 7 and from 7 to 12,8 practically does not change. The statistical significance of these centers also differs insignificantly. The character of influence of active centers from $\mathrm{pKa}$ from $-4,4$ to 0 changes essentially. if at filling of cement in concrete the increase in the maintenance of active centers was accompanied by decrease in strength parameters of concrete, at filling of sand in concrete on the contrary durability increases. Thus, it can be stated that the compressive strength of concrete (in this case, fine-grained) in the filling of sand in concrete is a function of the quantitative content of the active centers of a certain acidity on the surface of mineral fillers. In particular, the growth of the quantitative content of active centers on the surface of mineral fillers with pKa from 7 to 12.8 and from -4.4 to 0 leads to an increase in the strength of concrete, and the increase in intensity with pKa from 0 to 7 leads to a decrease in the strength of concrete. The revealed regularities allow using with a sufficient degree of accuracy the indicators of surface activity of disperse minerals as a criterion for determining the most effective way of their application in the composition of cement concretes. In this respect, it seems expedient, at intensity of the active centers on a surface of mineral fillers in the field of pKa from 0 to 7 to $10-10-3 \mathrm{mg}$-eqv/g to use a method of filling sand in concrete, and at intensity of the active centers on a surface of mineral fillers in the field of pKa from 0 to 7 more than $10-10-3 \mathrm{mg}$-eqv/g a method of filling cement in concrete. In this case, using the data on the quantitative content of active centers on the surface of mineral fillers, given in Table 1[13] it is possible to recommend for filling of cement concretes by the method of "filling of sand in concrete" using such fillers as: quartz sand, velvet sand, wastes of electrosmelting manufacture, and for filling of cement concretes by the method of "filling of cement in concrete" such fillers as: gliège, basalt, wastes of copper smelting manufacture, fly ash of thermal power station, zeolite-containing rocks.

\section{REFERENCES}

1. Schmidt M. Jahre Entwicklung bei Zement, Zusatsmittel und Beton. Ceitzum Baustoffe und Materialprüfung. Schriftenreihe Baustoffe. Geburgstag von Prof. Dr. Jng. Peter Schiesse. Heft 2. 2003, p. 189198.

2. Kleingelhöfer $P$. Neue Betonverflissiger auf Basis Policarboxilat. 13. 1997 Jbasil Weimar, Bd. 1, p. 491 495.

3. Frank D., Friedemann K., Schmidt D. Optimisierung der Mischung sowie Verifizirung der Eigenschaften Saueresistente Hochleistungbetone. Betonwerk+Fertigteil-Technik. 2003.№ 3. p. 30-38.

4. Richard P., Cheurezy M. Composition of Reactive Powder Concrete. Skientific Division Bougies. // Cement and Concrete Research, Vol. 25. No. 7, 1995. - pp. 1501 1511.

5. Usherov-Marshak A.V. Modern concrete and its technologies / Coll. "Concrete and reinforced concrete". St. Petersburg, Izd. "Slavutich", 2009, p.20-24.

6. Aitchin P.-C., Neville A. High- Performance Concrete Demystified. Coner. Intern. 1993, Vol. 15, №1, p.21-26.

7. Edvard G., Nawy P. Fundaments of High Performance Concrete. Sec. ed. Willy. 2001. - - 302p.

8. 8.Adylkhodzhaev A.I. Fundaments of High Performance Concrete A.I.Adilkhodzhaev, V.I.Solomatov.-Tashkent, Izd-in FAN RUz.1993.-214p.

9. 9.Vysotsky S.A. Mineral additives for concrete / S.A.Vysotsky//Beton and reinforced concrete, 1994. -№2 -p.7-10.

10. 10.Tahirov, M.K. About the nature of the interphase interactions of the polycarboxylate superplasticizer and basalt filler (in Russian) / M.K.Tahirov, V.M.Tsoi/// Resource-saving technologies in construction Intercollection of scientific articles, issue 4, Tashkent, Tashkent, Tashkent, 2009.-p.3-12.

11. 11.Tsoi, V.M. Methodological bases of the optimal design of the compositions and management of the physicochemical properties of the multi-component highquality concretes // Abstract of the doctoral dissertation on technical sciences (DSc) // Tashkent, TASI, 2017.$36 \mathrm{p}$.

12. 12.Nechiporenko, A.P. Donor-acceptor surface properties of the solid oxides and chalcogenides. Doctoral diss., L. 1995, -523p.

13. Adylkhodzhaev A.I., Makhamataliev I.M., Tsoi V.M., Shaumarov S.S. Forecasting of the effectiveness of mineral fillers in cement composites // Scientific and Technical Bulletin of Bryansk State University, Bryansk, 2019, №1.-p.105-112. 